\title{
Cannabis abuse and self-mutilation
}

\section{Yassa $\mathrm{AH}^{*}$ and George SM}

Assistant Professor, Department of Forensic and Clinical Toxicology, Faculty of Medicine, Assiut University, Egypt

${ }^{*}$ Corresponding author: Yassa AH, Assistant Professor, Department of Forensic and Clinical Toxicology, Faculty of Medicine, Assiut University, Egypt, E-mail: heba612@hotmail.com

Citation: Yassa AH, George SM (2016) Cannabis abuse and self-mutilation. J Forensic Sci Criminol 4(5): 505. doi: 10.15744/2348-9804.4.505

Received Date: November 30, 2016 Accepted Date: December 27, 2016 Published Date: December 29, 2016

\begin{abstract}
Background: Self-mutilating patient is an unusual psychiatric patient in the emergency department. An underlying cause for this psychiatric condition should be known for rehabilitation after saving the life of the patient. Drug abuse is very common and important cause should be searched for in these cases.

Case Presentation: A 35 years old Egyptian male presented to the Emergency Department with severe deep self-inflicted cuts wound by razor associated with hemodynamic shock. After stabilization and urine analysis, he was a cannabis addict.

Conclusions: Relationship between drug abuse, particularly cannabis and self-mutilation behavior is increased. Cannabis abuse is so common in our country. Discovery and rehabilitation of the addicts through rehabilitation programs will maintain large numbers of young youth in the working age group safe.
\end{abstract}

Keywords: Mutilation; Cannabis; Rehabilitation; Addiction; Psychosis

\section{Introduction}

Self-mutilation or self-harming behavior defined as deliberate destruction or alteration of body tissue in the absence of conscious suicidal intention [1-9]. The incidence of self-injurious among adolescent increased around the world. It is associated with a range of psychiatric difficulties [10-13].

Cannabis is the world's most widely used illicit substance. There are between 119 million and 224 million cannabis users worldwide. Cannabis seizure and eradication data suggest that the production of cannabis herb is increasingly widespread, The Americas, followed by Africa, remain the main production and consumption regions for cannabis herb, with about three quarters of all cannabis herb seizures worldwide taking place in the Americas in 2014, the largest amounts in North America, while Africa accounted for 14 per cent of all cannabis herb seizures and Europe for 5 per cent. On the other hand, Europe, North Africa and the Near and Middle East remain the principal markets for cannabis resin, the majority of which continues to be produced in Morocco and Afghanistan, as reflected in information provided by Member States on the sources of cannabis resin seized. The relative importance of cannabis resin and herb varies by region, with cannabis resin being dominant in the Near and the Middle East and South-West Asia, cannabis resin and herb markets being comparable in size in North Africa and Europe. Data from Africa is hard to come, but seizure data suggest that the herb is also the dominant form of cannabis in that region, except in North Africa where the resin is predominant $[14,15,26]$.

Psychosis is one of the most serious among the adverse effects associated with cannabis use. The persons who develop psychosis experience, the onset of psychosis about 2-3 years earlier if they are cannabis users; this effect is not observed with alcohol or other substance use. Experimental studies in humans show that cannabinoids and cannabis can induce psychotic symptoms. The causal effect of cannabis in anticipating, triggering or exacerbating psychosis in vulnerable individuals and in worsening the course and outcome of the illness in those who continue to use the substance [16-19].

\section{Case report}

A 35 years old male presented to the emergency department, Assiut University Hospital with self-inflicted, deep cut wound in the left wrist. He was a farmer with a primary degree of education, married for five years with two children. There was a history of many quarrels with his wife and children. The patient was found on the floor of his flat by his cousin, catching a razor by the other hand. He was smashing the window glass and other home furniture's. His cousin tried to take the razor from his right hand and took him rapidly with other neighbors to the hospital. The patient had no previous medical or psychiatric history, according to the history taken from his cousin, and according to his words with no addiction history, later on and after the analysis he said that he was taken cannabis from five years ago. (Figure 1, 2 and 3). 


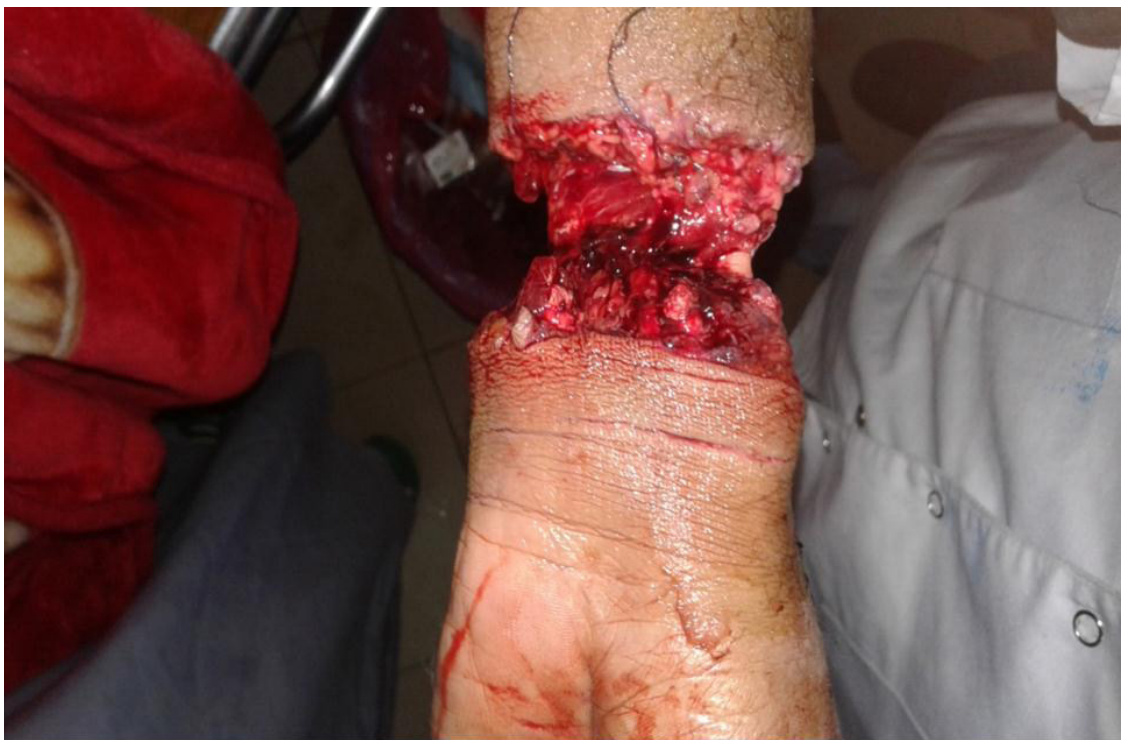

Figure 1: A photo shows initial emergency department entry of the patient with severe cut wound

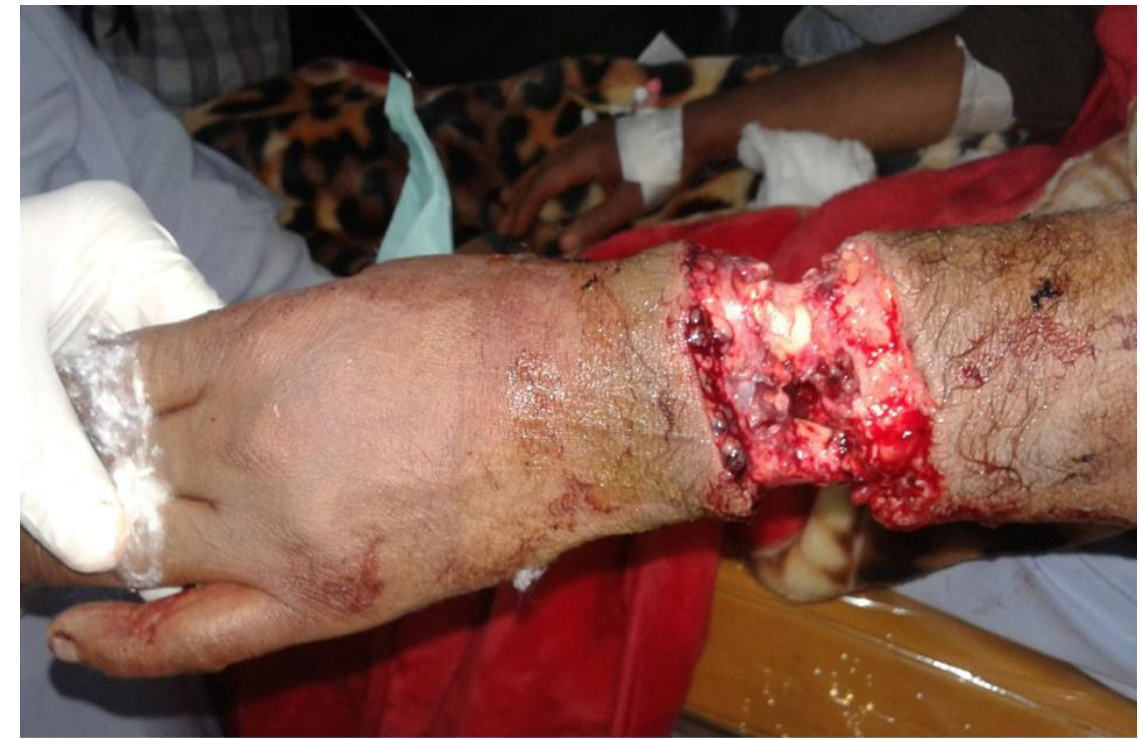

Figure 2: A photo shows initial emergency department entry of the patient with severe cut wound dorsum of the hand

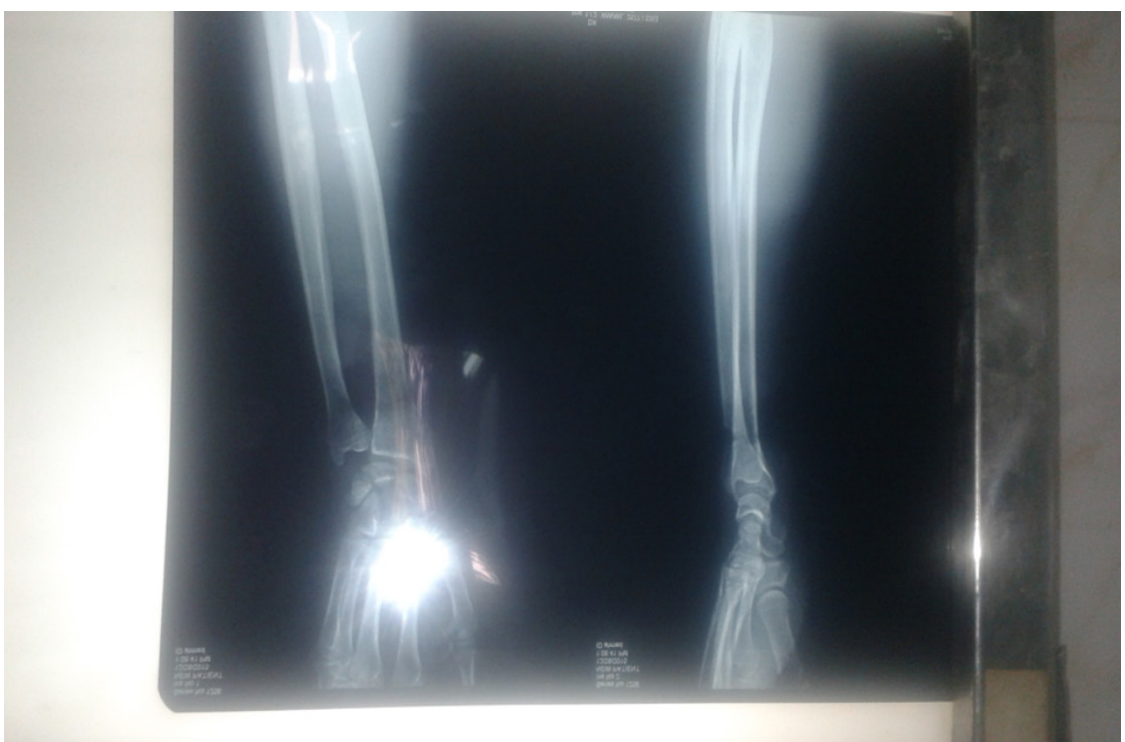

Figure 3: $\mathrm{X}$ ray photo initial emergency department entry of the patient antroposterior and lateral view 
On admission to the emergency department, standard fluid resuscitation was initiated with urgent surgery, which required amputations of his left hand at the level of the wrist joint.

Once the patient was stabilized both medically and psychologically, his history was reviewed and revealed that prior to his acute psychotic outbreak, he expelled his wife and children from the house. But he denied that he took any medication or abuse drugs.

Urine sample was taken from the patient immediately after his arrival to the hospital and before taken any medication (after taking his consent) and underwent immunoassay drug analysis for drug abuse (Cannabis - Cocaine - Amphetamines - Morphine Tramadol - Barbiturates - Benzodiazepines). The patient was positive for cannabis, after that the result were confirmed by using High performance liquid chromatography (HPLC).

After the urine test, the patient said that there was a long history of cannabis abuse (in the form of cannabis leaves = bango, and cannabis resin) for more than 10 years.

The patient is now in good health and referred to the psychotic clinic to attend group therapy.

\section{Discussion}

This case report is one to elucidate a link between cannabis abuse and paranoia leading to self-mutilation. Through deep cut wound in the wrist joint. This patient was able to work and had a meaningful and productive life.

Although Cannabis is banned in Egypt. It continues to spread between Egyptians, with different age group and level of education. All forms of cannabis can be used in Egypt, leaves (which called bango are very common) - resin and hash.

A possible explanation for the increased demand may be due to many factors include that cheap price, availability, and it is considered as a safe plant, not as harm as other drugs of abuse. It is very common to see cannabis leaves used in happy occasions and weddings also can be used in quarrels either alone or in combination with other drugs of abuse.

According to Starr, 2004 self-mutilating behavior is a symptom seen in both men and women with various psychiatric disorders [20]. Many theories consider self-mutilation as a method to reduce distress or tension, an expression of anger, or manipulative behavior. Some authors link this behavior to borderline personality disorder.

There is a relationship between dopamine and self-mutilation injuries. High doses of dopaminergic agonists, such as amphetamine, can engender self-mutilation. Psychoactive substances (such as cocaine and cannabis) alter synaptic transmission by interacting with dopamine transporters, and that their dopaminergic action is one of their most important neurological properties. Gorea and Lombard report that the dopaminergic system may participate in mutilating behavior in rats [21]. Many studies found a relation between cannabis addiction and the psychotic behavior and self-mutilation or self-destruction, some of them explain that for the dopaminergic effects, and others relate that for the genetic vulnerability which increases the risk of developing psychosis and cognitive impairment [22-24].

Some studies indicate that frequent use of cannabis doubles the risk of psychotic disorders and schizophrenia. Cannabis can lead to disruption of endogenous cannabinoid signaling and functioning. It is apparent that cannabis use induces manic symptoms and aggravates it $[25,26]$.

\section{Conclusion}

Cannabis abuse is so common in our country. Discovery and rehabilitation of the addicts through rehabilitation programs will maintain large numbers of young youth in the working age group safe and away from psychiatric complications of cannabis.

\section{Ethics}

All procedures done followed the ethical standards of the Assiut University Faculty of Medicine, and the Helsinki Declaration. No data about the name of the patient were written as patient name, or his ticket number. The photos in the paper did not contain any data or face of the patient.

\section{References}

1. Pattison EM, Kahan J (1983) The deliberate self-harm syndrome. Am J Psychiatry 140: 867-72.

2. Brooksbank DJ (1985) Suicide and parasuicide in childhood and early adolescence. Br J Psychiatry 146: 459-63.

3. Coons PM (1992) Self amputation of the breasts by a male with schizotypal personality disorder. Hosp Community Psychiatry 43 : $175-6$.

4. Tantam D, Whittaker J (1992) Personality disorder and self wounding. Br J Psychiatry 161: 451-64.

5. Shearer SL (1994) Phenomenology of self-injury among inpatient women with borderline personality disorder. J Nervous Ment Dis 182: 524-6.

6. Herpertz S (1995) Self-injurious behavior: Psychopathological and nosological characteristics in subtypes of self-injurers. Acta Psychiatr Scand 91: 57-68.

7. Solomon Y, Farrand J (1996) "Why don't you do it properly?" Young women who self-injure. J Adolesc 19: 111-9.

8. Patton GC, Harris R, Carlin JB, Hibbert M, Coffey C, et al. (1997) Adolescent suicidal behaviors: A population based study of risk. Psychol Med 27: 715-24. 
9. Taiminen TJ, Kallio-Soukainen K, Nokso-Koivisto H, Kaljonen A, Helenius H (1998) Contagion of deliberate self-harm among adolescent inpatients. J Am Acad Child Adolesc. Psychiatry (1998) 37: 211-7.

10. Nock MK, Joiner TE, Gordon KH, Lloyd-Richardson E, Prinstein MJ (2006) Nonsuicidal self-injury among adolescents: diagnostic correlates and relation to suicide attempts. Psychiatry Res 144: 65-72.

11. Jacobson CM, Muehlenkamp JJ, Miller AL, Turner JB (2008) Psychiatric impairment among adolescents engaging in different types of deliberate self-harm. J Clin Child Adolesc Psychol 37: 363-75.

12. Nock MK (2010) Self-injury. Ann Rev Clin Psychol 6: 339-63.

13. Muehlenkamp J, Claes L, Havertape L, Plener P (2012) International prevalence of adolescent nonsuicidal self-injury and deliberate self-harm. Child Adolesc Psychiatry Ment Health 6: 10.

14. European Monitoring Centre for Drugs and Drug Addiction, Annual Report (2011) The State of the Drugs Problem in Europe (Luxembourg, Publications Office of the European Union).

15. World drug report (2012) United Nation Office on Drugs and Crime.

16. Andrade C (2016) Cannabis and Neuropsychiatry, 2: The Longitudinal Risk of Psychosis as an AdverseOutcome. J Clin Psychiatry.77: e739-42.

17. Buchy L, Mathalon DH, Cannon TD, Cadenhead KS, Cornblatt BA., et al. (2016) Relation between cannabis use and subcortical volumes in people at clinical high risk of psychosis. Psychiatry Res 2: 3-9.

18. Schoeler T, Monk A, Sami MB, Klamerus E, Foglia E, et al. (2016) Continued versus discontinued cannabis use in patients with psychosis: a systematic review and meta-analysis. Lancet Psychiatry 3: 215-25.

19. Yassa HA, Dawood AW, Shehata MM, Abdel-Hady RH, et al. (2010) Risk factors for bango abuse in upper Egypt. Environ Toxicol Pharmacol 28: 397-402. 20. Starr DL (2004) Understanding those who self mutilate. J Psychosoc Nurs Ment. Health Serv, 42: 32-8.

21. Gorea E, Lombard MC (1984) The possible participation of a dopaminergic system in mutilating behavior in rats with forelimb deafferentation. Neurosci Lett, 48: 75-80.

22. Linszen D, Van Amelsvoort T (2007) Cannabis and psychosis: an update on course and biological plausible mechanisms. Curr Opin Psychiatry 20: 116-20.

23. Ahsaini M, Tazi F, Khalouk A, Lahlaidi K, et al. (2011) Bilateral testicular self-castration due to cannabis abuse: a case report. J Med Case Reports 5: 404.

24. Meijer K, Russo R, Adhvaryu D (2014) Smoking Synthetic Marijuana Leads to Self-Mutilation Requiring Bilateral Amputations. Orthopedics 37: e391- 4.

25. Leweke FM, Koethe D (2004) Cannabis and psychiatric disorders: it is not only addiction. Addict Biol 13: $264-75$.

26. World drug report (2016) United Nation Office on Drugs and Crime.

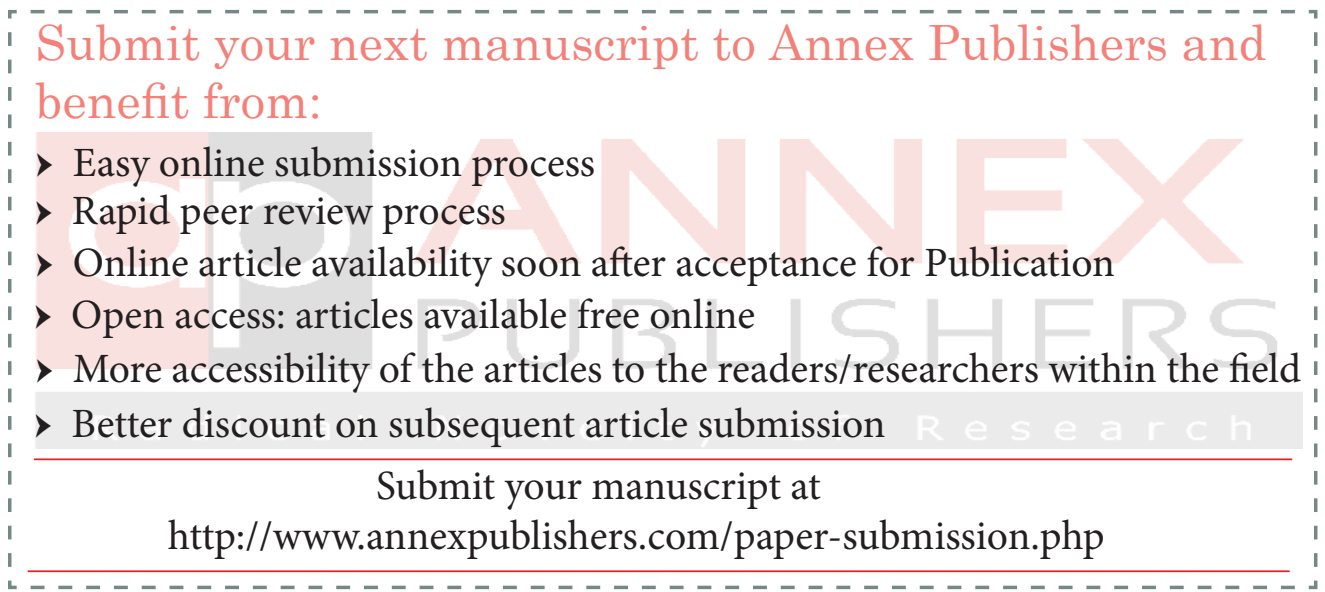

